\title{
Role of APOE and Age at Enrollment in the Alzheimer's Disease Anti-Inflammatory Prevention Trial (ADAPT)
}

\section{Lea T. Drye Peter P. Zandi for the ADAPT Research Group}

Departments of Epidemiology and Mental Health, Bloomberg School of Public Health, The Johns Hopkins University, Baltimore, Md., USA

\section{Key Words}

Prevention · Clinical trial $\cdot$ Alzheimer's disease $\cdot$ Apolipoprotein E $\cdot$ Age

\begin{abstract}
Background: The Alzheimer's Disease Anti-inflammatory Prevention Trial (ADAPT) tested whether non-steroidal anti-inflammatory drugs (NSAIDs) can prevent Alzheimer's disease (AD). The results were null. We analyzed ADAPT data to examine if the effects of NSAIDs on AD risk differed depending upon APOE genotype or age as has been suggested by previous observational studies. Methods: ADAPT randomized 2,528 cognitively intact older adults to either celecoxib, naproxen sodium or placebo; 2,388 participants provided blood samples for APOE genotyping. Proportional hazards regression was used to estimate the effects of naproxen or celecoxib versus placebo on incident AD by age at enrollment and APOE genotype. Results: The proportion of subjects providing a biological sample did not differ between the treatment groups. In models of AD risk, none of the tests for 2-way interactions between either NSAID and age or APOE genotype were significant ( $p>0.05$ ). Conclusions: The data did not support the hypothesis that the association between NSAIDs and AD risk differed by age or APOE genotype.
\end{abstract}


Drye et al.: Role of APOE and Age at Enrollment in the Alzheimer's Disease

Anti-Inflammatory Prevention Trial (ADAPT)

\section{Introduction}

Previous epidemiologic studies have found that non-steroidal anti-inflammatory drugs (NSAIDs) are associated with reduced risk of Alzheimer's disease (AD) [for a review, see 1]. Several of these studies have suggested the risk reduction may be greater among certain subgroups. In one study, NSAIDs were associated with reduced AD risk only among those with at least one high-risk $\varepsilon 4$ allele [2]. Several other studies noted similar albeit non-significant subgroup differences by APOE genotype [3-5]. Two other observational studies reported that the association between NSAIDs and reduced AD risk was greatest among the youngest old and diminished with increasing age $[2,6]$.

The Alzheimer's Disease Anti-inflammatory Prevention Trial (ADAPT) was designed to evaluate whether the nonselective NSAID naproxen sodium (Aleve ${ }^{\circledR}$, Bayer) or the selective cyclooxygenase-2 (COX-2) inhibitor celecoxib (Celebrex ${ }^{\circledR}$, Pfizer) prevent AD onset among cognitively intact elderly with a family history of AD. Primary results reported from the trial did not support the hypothesis that NSAIDs prevent AD or age-related cognitive decline $[7,8]$. This report describes analyses of ADAPT data to determine if the effect of the NSAIDs on AD incidence differed by APOE genotype or age at enrollment in the trial.

\section{Methods}

\section{Design Overview}

ADAPT was a randomized, placebo-controlled, primary prevention trial sponsored by the National Institute on Aging. Participants were assigned to the following parallel treatment groups in a 1:1:1.5 ratio: (a) naproxen (220 mg b.i.d.); (b) celecoxib (200 mg b.i.d.), or (c) placebo. Participants and personnel at the clinical sites were masked to treatment assignment using a double-placebo design [9]. The study protocol was reviewed and approved by all relevant institutional review boards.

ADAPT participants were recruited primarily through mailings to Medicare beneficiaries in areas surrounding the trial's six field sites in the United States (Baltimore, Md.; Boston, Mass.; Rochester, N.Y.; Seattle, Wash.; Sun City, Ariz.; Tampa, Fla.). Participants were aged 70 years or older, with a history of at least one first-degree relative with Alzheimer-like dementia. Participants underwent cognitive screening before enrollment to exclude those with dementia or other cognitive disorders.

Participants were enrolled from March 2001 to December 2004 and screened annually by an in-person cognitive assessment battery. In December 2004, enrollment and treatment administration were suspended earlier than planned following the announcement from the Adenoma Prevention with Celecoxib (APC) trial that the dose of celecoxib used in ADAPT produced substantially increased risks of cardiovascular death, myocardial infarction, and related events. The rationale for suspending both treatments in ADAPT has been fully discussed [10]. A subsequent analysis of ADAPT data did not show the same level of risk for celecoxib as those of the APC trial [11]. The follow-up of patients enrolled in ADAPT continued until a common closing date in February 2007. A detailed description of the ADAPT design and methods has been published [12].

\section{Outcome Assessment}

Participants with possible cognitive syndromes were identified using cognitive assessment batteries or via referral from study clinicians and were invited to return to a study clinic for a dementia evaluation visit. A description of the battery of tests and procedures used in ADAPT for cognitive assessments and dementia evaluations has been published [7]. 
The laboratory, neuroimaging, and cognitive battery results from the annual study visits and the dementia evaluation visit were reviewed by a diagnostic expert panel including the examining clinicians, other ADAPT physicians, and senior site neuropsychologists. When appropriate, the panel assigned diagnoses of dementia using the Diagnostic and Statistical Manual of Mental Disorders-IV criteria [13] and of Alzheimer's dementia using the National Institute of Neurological and Communicative Disorders and Stroke-Alzheimer's Disease and Related Disorders Association criteria [14].

\section{APOE Genotyping}

At enrollment, 5-7 ml of blood was collected from participants who consented to DNA banking. Whole-blood specimens were shipped at room temperature to the Johns Hopkins University Genetic Resources CORE Facility in Baltimore, Md., and DNA was extracted for genetic investigations. APOE genotyping was carried out using standard protocols with the NanoChip ${ }^{\circledR}$ Molecular Biology Workstation (Nanogen) platform.

\section{Data Analysis}

Pearson $\chi^{2}$ tests were used to compare participants who did and did not provide specimens for DNA banking. Naproxen and celecoxib were each compared with placebo. We evaluated time-to-occurrence of AD using the principle of intention-to-treat (ITT) with Cox proportional hazards regression models [15] excluding participants with no follow-up data. For those participants without an AD event, person-time was censored after the participants' last completed cognitive assessment. The event date for those participants with a diagnosis of $\mathrm{AD}$ was taken as the date of the relevant dementia evaluation visit. To test for different treatment effects by age and $A P O E$ genotype, we separately examined models with 2-way interactions between treatment and age category (dichotomized at the median baseline age; age $<74$ years vs. age $\geq 74$ years) or treatment and $A P O E$ genotype (dichotomized at one or more APOE $\varepsilon 4$ alleles vs. no $\varepsilon 4$ alleles). Models were adjusted for field site and 5-year age group (for models not including the dichotomized age variable). The resulting hazard ratios (HRs) were estimated with 95\% CIs and Wald p values using the PHREG procedure in SAS (SAS/STAT ${ }^{\circledR}$ software, version 9.2 of the SAS System for Windows; Copyright ${ }^{\circledR}$ 2002-2008 SAS Institute Inc., Cary, N.C., USA).

\section{Results}

The flow of participants through randomization and follow-up and the demographic characteristics of the entire randomized cohort have been shown in previous publications [7, $8,11]$. Briefly, 2,528 participants were randomized (placebo: 1,083; celecoxib: 726; naproxen: 719), and 2,071 participants had at least one follow-up visit (placebo: 895; celecoxib: 588; naproxen: 588).

A total of 2,388 participants provided DNA specimens for APOE genotyping. The proportion of participants providing specimens did not differ appreciably between the treatment groups. The proportion of participants not providing specimens was slightly higher for women than men ( 6.8 vs. $\left.4.5 \% ; \chi^{2}=6.6 ; \mathrm{p}=0.01\right)$ and varied significantly by race $(5.3 \%$ White, $18.9 \%$ African-American, $0 \%$ Hispanic, $13.6 \%$ other; $\chi^{2}=16.7, \mathrm{p}<0.01$ ) and marital status (4.5\% married, 9.5\% widowed, $15.4 \%$ separated, $6.4 \%$ divorced, $3.1 \%$ never married; $\left.\chi^{2}=21.6 ; \mathrm{p}<0.01\right)$. The proportion of participants not providing specimens also differed by clinic (5.0\% Baltimore, 8.7\% Boston, 4.4\% Rochester, 11.0\% Seattle, 1.1\% Sun City, 3.3\% Tampa; $\left.\chi^{2}=58.1 ; \mathrm{p}<0.01\right)$. 
Table 1. Baseline characteristics of ADAPT participants providing DNA

\begin{tabular}{|c|c|c|c|c|}
\hline & Total & Placebo & Celecoxib & Naproxen sodium \\
\hline Participants & 2,528 & 1,083 & 726 & 719 \\
\hline Provided DNA, n (\%) & $2,388(94.5)$ & $1,023(94.5)$ & $686(94.5)$ & $679(94.4)$ \\
\hline \multicolumn{5}{|l|}{ Age group, $\mathrm{n}(\%)$} \\
\hline $70-74$ years & $1,325(55.5)$ & $562(54.9)$ & $385(56.1)$ & $378(55.7)$ \\
\hline $75-79$ years & $754(31.6)$ & $324(31.7)$ & $214(31.2)$ & $216(31.8)$ \\
\hline $80-84$ years & $269(11.3)$ & $120(11.7)$ & $76(11.1)$ & $73(10.8)$ \\
\hline$\geq 85$ years & $40(1.7)$ & $17(1.7)$ & $11(1.6)$ & $12(1.8)$ \\
\hline \multicolumn{5}{|l|}{ Gender, n (\%) } \\
\hline Male & $1,307(54.7)$ & $573(56.0)$ & $365(53.2)$ & $369(54.3)$ \\
\hline Female & $1,081(45.3)$ & $450(44.0)$ & $321(46.8)$ & $310(45.7)$ \\
\hline \multicolumn{5}{|l|}{ Race/ethnic origin, n (\%) } \\
\hline White & $2,321(97.2)$ & $998(97.6)$ & $661(96.4)$ & $662(97.5)$ \\
\hline African-American & $30(1.3)$ & $9(0.9)$ & $11(1.6)$ & $10.0(1.5)$ \\
\hline Hispanic & $18(0.8)$ & $6(0.6)$ & $10(1.5)$ & $2(0.3)$ \\
\hline Other & $16(0.7)$ & $9(0.9)$ & $3(0.4)$ & $4(0.6)$ \\
\hline Refused & $3(0.1)$ & $1(0.1)$ & $1(0.1)$ & $1(0.1)$ \\
\hline \multicolumn{5}{|l|}{ Education, n (\%) } \\
\hline Less than high school & $99(4.2)$ & $37(3.6)$ & $28(4.1)$ & $34(5.0)$ \\
\hline High school graduate & $475(19.9)$ & $212(20.7)$ & $144(21.0)$ & $119(17.5)$ \\
\hline Some college & $655(27.4)$ & $272(26.6)$ & $191(27.8)$ & $192(28.3)$ \\
\hline College degree & $460(19.3)$ & $215(21.0)$ & $130(19.0)$ & $115(16.9)$ \\
\hline Postgraduate education & $699(29.3)$ & $287(28.1)$ & $193(28.1)$ & $219(32.3)$ \\
\hline \multicolumn{5}{|l|}{ Marital status, $\mathrm{n}(\%)$} \\
\hline Married & $1,736(72.7)$ & $734(71.8)$ & $486(70.8)$ & $516(76.0)$ \\
\hline Widowed & $417(17.5)$ & $183(17.9)$ & $129(18.8)$ & $105(15.5)$ \\
\hline Separated & $11(0.5)$ & $7(0.7)$ & $3(0.4)$ & $1(0.1)$ \\
\hline Divorced & $160(6.7)$ & $73(7.1)$ & $49(7.1)$ & $38(5.6)$ \\
\hline Never married & $63(2.6)$ & $25(2.4)$ & $19(2.8)$ & $19(2.8)$ \\
\hline Not reported & $1(0.0)$ & $1(0.1)$ & 0 & 0 \\
\hline \multicolumn{5}{|l|}{ APOE alleles, $\mathrm{n}(\%)$} \\
\hline$\varepsilon 2 / \varepsilon 2$ & $7(0.3)$ & $3(0.3)$ & $3(0.4)$ & $1(0.1)$ \\
\hline$\varepsilon 2 / \varepsilon 3$ & $253(10.6)$ & $114(11.1)$ & $74(10.8)$ & $65(9.6)$ \\
\hline$\varepsilon 2 / \varepsilon 4$ & $82(3.4)$ & $34(3.3)$ & $23(3.4)$ & $25(3.7)$ \\
\hline$\varepsilon 3 / \varepsilon 3$ & $1,286(53.9)$ & $549(53.7)$ & $353(51.5)$ & $384(56.6)$ \\
\hline$\varepsilon 3 / \varepsilon 4$ & $695(29.1)$ & $296(28.9)$ & $216(31.5)$ & $183(27.0)$ \\
\hline$\varepsilon 4 / \varepsilon 4$ & $65(2.7)$ & $27(2.6)$ & $17(2.5)$ & $21(3.1)$ \\
\hline
\end{tabular}

Table 1 shows the demographic characteristics of the 2,388 participants who provided specimens overall and by treatment group. The median age at randomization was 74 years; slightly more males than females were included, and more than $97 \%$ of the participants were white. Approximately one-third of the participants had at least one APOE $\varepsilon 4$ allele; only $3 \%$ had homozygous $\varepsilon 4$. More than half of the participants were homozygous for $\varepsilon 3$.

The incidence of $\mathrm{AD}$ was higher among participants with one $(\mathrm{HR}=2.4,95 \% \mathrm{CI}: 1.3-$ $4.4, \mathrm{p}<0.01)$ or two (HR $=6.2,95 \% \mathrm{CI}: 2.3-16.6, \mathrm{p}<0.01)$ APOE $\varepsilon 4$ alleles as compared to those with no $\varepsilon 4$ alleles. The incidence of $\mathrm{AD}$ was higher in participants older than 74 years compared to those younger than 74 years, although the confidence interval for the hazard ratio included one ( $\mathrm{HR}=1.3,95 \% \mathrm{CI}: 0.7-2.3, \mathrm{p}=0.41)$.

The 2-way tests for interaction did not provide support for the hypothesis that the treatment effects differed by age (celecoxib-by-age interaction $\mathrm{p}$ value $=0.66$, naproxen-byage interaction $\mathrm{p}$ value $=0.72$ ) or by $A P O E$ genotype (celecoxib-by- $\varepsilon 4$ status interaction $\mathrm{p}$ 
Table 2. Incidence of $\mathrm{AD}$ by treatment group, $A P O E$ alleles and age

\begin{tabular}{|c|c|c|c|c|c|c|c|c|}
\hline & \multicolumn{2}{|c|}{ Placebo } & \multicolumn{3}{|l|}{ Celecoxib } & \multicolumn{3}{|l|}{ Naproxen } \\
\hline & \multicolumn{2}{|c|}{ rate/100 $\mathrm{PY} \mathrm{x} / \mathrm{N}$} & \multicolumn{2}{|c|}{ rate/100 $\mathrm{PY} \mathrm{x} / \mathrm{N}$} & \multirow[t]{2}{*}{$\mathrm{HR}(95 \% \mathrm{CI})$} & \multicolumn{2}{|c|}{ rate/100 $\mathrm{PY} \mathrm{x} / \mathrm{N}$} & \multirow[t]{2}{*}{ HR $(95 \%$ CI $)$} \\
\hline \multicolumn{7}{|l|}{ Model 1} & & \\
\hline \multicolumn{9}{|c|}{ Presence of APOE $\varepsilon 4$ alleles } \\
\hline 0 APOE $\varepsilon 4$ alleles & 0.6 & $12 / 666$ & 0.6 & $8 / 430$ & $0.93(0.38-2.30)$ & 0.5 & $7 / 450$ & $0.80(0.31-2.06)$ \\
\hline 1-2 APOE $\varepsilon 4$ alleles & 1.5 & $17 / 357$ & 1.7 & $14 / 256$ & $1.14(0.56-2.33)$ & 1.3 & $9 / 229$ & $0.91(0.41-2.05)$ \\
\hline Missing APOE data & & $1 / 60$ & & $2 / 40$ & & & $2 / 40$ & \\
\hline \multicolumn{9}{|l|}{ Model 2} \\
\hline \multicolumn{9}{|l|}{ Baseline age } \\
\hline$<74$ years & 0.7 & $12 / 498$ & 0.7 & $7 / 320$ & $0.97(0.38-2.47)$ & 0.8 & $8 / 328$ & $1.00(0.41-2.46)$ \\
\hline$\geq 74$ years & 1.0 & $18 / 585$ & 1.3 & $17 / 406$ & $1.25(0.64-2.43)$ & 0.8 & 10/391 & $0.82(0.38-1.78)$ \\
\hline \multicolumn{9}{|c|}{$\begin{array}{l}\mathrm{x} / \mathrm{N}=\text { Number of events divided by the number of persons at risk; PY = cumulative person-years of follow-up; PYs can } \\
\text { be calculated as the number of events/(rate/100). Event is defined as possible or probable AD based on consensus conference. } \\
\text { Hazard ratios and } 95 \% \text { confidence intervals (NSAID vs. placebo) were calculated using Cox proportional hazards regres- } \\
\text { sion. Time to event is from randomization to the date of the associated dementia evaluation. Time to censor is from ran- } \\
\text { domization to the most recent cognitive assessment. Models included adjustment for stratification variables of field site } \\
\text { (both models) and 5-year age group (model } 1 \text { only). }\end{array}$} \\
\hline
\end{tabular}

value $=0.82$, naproxen-by- $\varepsilon 4$ status interaction $\mathrm{p}$ value $=0.90$ ). The HRs for each NSAID versus placebo are shown in table 2 stratified by the presence of APOE $\varepsilon 4$ alleles (model 1) and age category (model 2).

\section{Discussion}

ADAPT was carried out to test the hypothesis that NSAIDs prevent the onset of AD. The primary results did not provide any support for this hypothesis. The source of the discrepant results between the randomized trial and previous observational studies has been the focus of much debate [1]. Motivated by findings of several previous observational studies that the effects of NSAIDs may be greater among the youngest old or those with one or more APOE $\varepsilon 4$ allele, we analyzed ADAPT data to test for subgroup differences by age or APOE genotype that might explain the discrepancies between the observational and randomized studies. We found no evidence for such subgroup differences.

This is the first randomized study of NSAIDs and AD to test for subgroup differences by age or $A P O E$ genotype. Randomized trials are considered the gold standard for establishing causal relationships in epidemiology. However, the current study was not designed to test for treatment by genotype or age interactions and may not have had sufficient sample size to rule out important differences in treatment effects by age or APOE genotype. For instance, the estimated hazard ratio for naproxen versus placebo in the subgroup with APOE $\varepsilon 4$ alleles was close to 1.0 (i.e. $\mathrm{HR}=0.91$ ), but the confidence interval contained values that would probably be regarded as clinically significant, i.e. potentially a $60 \%$ reduction in AD incidence. Similarly for celecoxib versus placebo in those with $\varepsilon 4$ alleles, the wide confidence intervals meant that we are unable to rule out a $40 \%$ reduction in AD incidence. The current findings do argue, however, against subgroup effects on $\mathrm{AD}$ incidence of these magnitudes or greater. 


\section{Funding}

National Institute on Aging (NIA), U01 AG15477.

\section{Appendix 1: ADAPT Research Group}

\section{Clinical Centers}

Boston University School of Medicine, Boston, Mass.: Robert Green, MD (director); Sanford Auerbach, MD (associate director); Robert Stern, PhD (neuropsychologist); Patricia Boyle, $\mathrm{PhD}$ (previous neuropsychologist); Dawn Cisewski, $\mathrm{PhD}$ (previous neuropsychologist); Jane Mwicigi, MD (coordinator); Mary-Tara Roth, RN, MSN (previous coordinator); Lorraine Baldwin; Margaret Brickley, RN, NP; Patrick Compton, RN; Debra Hanna, RN; Sylvia Lambrechts; Janet Nafissi, MSN, APRN; Andrea Packard, MD, PhD; Mayuri Thakuria, MD.

Johns Hopkins School of Medicine, Baltimore, Md.: Constantine Lyketsos, MD (director); Martin Steinberg, MD (associate director); Jason Brandt, $\mathrm{PhD}$ (neuropsychologist); Julia J. Pedroso, RN (coordinator); Alyssa Bergey; Themos Dassopoulos, MD; Melanie Dieter; Carol Gogel, RN; Chiadi Onyike, MD; Lynn Smith; Veronica Wilson-Sturdivant; Nadine Yoritomo, RN.

The Roskamp Institute Memory Clinic, Tampa, Fla.: Michael Mullan, MD, PhD (director); Cheryl Luis, $\mathrm{PhD}$ (associate director, neuropsychologist); Timothy Crowell, PsyD (previous associate director, neuropsychologist); Julia Parrish (coordinator); Theavy Chea; Scott Creamer; Melody Brooks Jayne, MD; Antoinette Oliver; Summer Price; Joseph Zolton.

Sun Health Research Institute, Sun City, Ariz.: Marwan Sabbah, MD (director); Joseph Rogers, $\mathrm{PhD}$ (associate director); Donald Connor, $\mathrm{PhD}, \mathrm{PhD}$ (neuropsychologist); Carolyn Liebsack, RN (coordinator); Nancy Thompson, RN (previous coordinator); Joanne Ciemo, MD; Kathryn Davis; Theresa Hicksenhiser; Sherry Johnson-Traver; Healther Kolody; Lisa Royer, RN; Nina Silverberg, PhD; Deborah Tweedy, RN, MSN, CNP.

University of Rochester School of Medicine, Rochester, N.Y.: M. Saleem Ismael, MD (director); Pierre Tariot, MD (previous director); J. Michael Ryan, MD (previous associate director); Robin Henderson-Logan, PhD (neuropsychologist); Colleen McCallum (coordinator); Laura Jakimovick, RN; Kara Jones, RN; Anton Porsteinson, MD; Arlene Pustalka, RN; Susan Salem-Spencer, RN; Asa Widman; Helen Decker.

Veteran Affairs Puget Sound Health Care System and University of Washington School of Medicine, Seattle, Wash.: Suzanne Craft, $\mathrm{PhD}$ (director); Mark Fishel, MD (associate director); Laura Baker, PhD (neuropsychologist); Deborah Dahl, RN (coordinator); Kathleen Nelson, RN (previous coordinator); Susan Bigda, RN; Yoshie Biro; Ruth Boucher, RN; Nickolas Dasher; Edward DeVita, MD; Grace Garrett; Austin Hamm; Jeff Lindsey; Laura SissonsRoss.

\section{Resource Centers}

Coordinating Center: Johns Hopkins Bloomberg School of Public Health, Baltimore, Md.: Curtis L. Meinert, PhD (director); Barbara K. Martin, PhD (deputy director); Bonnie Piantadosi (coordinator); Robert Casper; Michele Donithan; Hsu-Tai Liu, MD; Steven Piantadosi, MD, PhD; Anne V. Shanklin; Paul Smith.

Office of Chair: Veteran Affairs Puget Sound Health Care System, Seattle, Wash.: John Breitner, MD (director); Jane Anau (coordinator); Melissa Montero (previous coordinator); Janette Negele (previous coordinator); Elizabeth Aigbe; Jill Dorje; Brenna Cholerton, $\mathrm{PhD}$. 
Drye et al.: Role of APOE and Age at Enrollment in the Alzheimer's Disease Anti-Inflammatory Prevention Trial (ADAPT)

Project Office: National Institute on Aging, Bethesda, Md.: Neil Buckholtz, PhD (project officer); Laurie Ryan, $\mathrm{PhD}$ (project officer); Susan Molchan, MD (previous project officer).

\section{Steering Committee}

Voting: Denis Evans (chair since March 2005, Rush-Presbyterian-St. Luke's Medical Center, Chicago, Ill.; Curtis Meinert, through February 2005); John Breitner; Jason Brandt; Neil Buckholtz; Suzanne Craft; Robert Green; M. Saleem Ismail (since December 2005); Constantine Lyketsos; Barbara Martin; Curtis Meinert; Susan Molchan; Michael Mullan; Steven Piantadosi; Marwan Sabbagh; Pierre Tariot (through October 2005).

Consultants: Themistocles Dassopoulos, MD, Johns Hopkins School of Medicine, Baltimore, Md.; Claudia Kawas, MD, University of California Irvine, Irvine, Calif.; Leon Thal (deceased), MD, University of California San Diego, La Jolla, Calif.; Kathleen Welsh-Bohmer, PhD, Duke University Medical Center, Durham, N.C.; Andrew Whelton, MD; Hunt Valley, MD.

\section{Treatment Effects Monitoring Committee}

Voting: C. Morton Hawkins, PhD (chair since December 2002, Frontier Science and Technology Research Foundation, Madison, Wisc.; Donald Berry, PhD, through April 2002); Bernard Carroll, MBBS, PhD, Pacific Behavioral Research Foundation, Carmel, Calif.; Ronald Petersen, MD, PhD, Mayo Clinic, Rochester, Minn.; Bruce Psaty, MD, PhD, University of Washington, Seattle, Wash.; Thomas Schnitzer, MD, PhD, Northwestern University, Chicago, Ill.; Dallas High, PhD (through June 2004).

Non-voting: Neil Buckholtz; Denis Evans; Curtis Meinert.

\section{References}

-1 Szekely CA, Zandi PP: Non-steroidal anti-inflammatory drugs and Alzheimer's disease: the epidemiological evidence. CNS Neurol Disord Drug Targets 2010;9:132-139.

-2 Szekely CA, Breitner JC, Fitzpatrick AL, Rea TD, Psaty BM, Kuller LH, Zandi PP: NSAID use and dementia risk in the Cardiovascular Health Study: role of APOE and NSAID type. Neurology 2008; 70:17-24.

-3 Cornelius C, Fastbom J, Winblad B, Viitanen M: Aspirin, NSAIDs, risk of dementia, and influence of the apolipoprotein E epsilon 4 allele in an elderly population. Neuroepidemiology 2004;23:135143.

-4 in t' Veld BA, Ruitenberg A, Hofman A, Launer LJ, van Duijn CM, Stijnen T, Breteler MM, Stricker BH: Nonsteroidal antiinflammatory drugs and the risk of Alzheimer's disease. N Engl J Med 2001; 345:1515-1521.

-5 Yip AG, Green RC, Huyck M, Cupples LA, Farrer LA: Nonsteroidal anti-inflammatory drug use and Alzheimer's disease risk: the MIRAGE Study. BMC Geriatr 2005;5:2.

-6 Zandi PP, Anthony JC, Hayden KM, Mehta K, Mayer L, Breitner JC: Reduced incidence of AD with NSAID but not H2 receptor antagonists: the Cache County Study. Neurology 2002;59:880886.

-7 Lyketsos CG, Breitner JC, Green RC, Martin BK, Meinert C, Piantadosi S, Sabbagh M: Naproxen and celecoxib do not prevent AD in early results from a randomized controlled trial. Neurology 2007;68: 1800-1808.

8 Martin BK, Szekely C, Brandt J, Piantadosi S, Breitner JC, Craft S, Evans D, Green R, Mullan M: Cognitive function over time in the Alzheimer's Disease Anti-inflammatory Prevention Trial (ADAPT): results of a randomized, controlled trial of naproxen and celecoxib. Arch Neurol 2008;65:896-905.

-9 Martin BK, Meinert CL, Breitner JC: Double placebo design in a prevention trial for Alzheimer's disease. Control Clin Trials 2002;23:93-99. 
Drye et al.: Role of APOE and Age at Enrollment in the Alzheimer's Disease Anti-Inflammatory Prevention Trial (ADAPT)

10 Steering Committee of the Alzheimer's Disease Anti-inflammatory PreventionTrial: Statement from the Steering Committee of the Alzheimer's Disease Anti-inflammatory Prevention Trial (ADAPT) for communication to the FDA Arthritis Advisory Committee and the Drug Safety and Risk Management Advisory Committee, 2005.

-11 ADAPT Research Group: Cardiovascular and cerebrovascular events in the randomized, controlled Alzheimer's Disease Anti-Inflammatory Prevention Trial (ADAPT). PLoS Clin Trials 2006;1:e33.

-12 Meinert CL, McCaffrey LD, Breitner JC: Alzheimer’s Disease Anti-inflammatory Prevention Trial: design, methods, and baseline results. Alzheimers Dement 2009;5:93-104.

13 American Psychiatric Association: Diagnostic and Statistical Manual of Mental Disorders, ed 4. Washington, American Psychiatric Association, 2000.

-14 McKhann G, Drachman D, Folstein M, Katzman R, Price D, Stadlan EM: Clinical diagnosis of Alzheimer's disease: report of the NINCDS-ADRDA Work Group under the auspices of Department of Health and Human Services Task Force on Alzheimer's Disease. Neurology 1984;34:939-944.

15 Cox DR: Regression models and life-tables. J R Stat Soc Series B 1972;34:187-220. 